upon the matter in a paragraph or so, stated that he had been bled to control inward bleeding; but the physician's name did not appear. Consequently I had no means of inquiring directly. I presume that there are many other doctors besides myself who supposed the statements true, as they went uncontradicted.

So much in explanation, and $I$ am taking the first occasion after seeing Dr. McCormack's letter to withdraw my statement which, though not wilfully, has done him such injustice. Indeed, the actual treatment as he explains it could not be improved upon. It was wise and followed the most modern surgical standards. The use of hot, intravenous saline infusion so promptly was exactly the right thing done at the right time. I can but express surprise at a report becoming spread abroad, therefore, so at absolute variance with the facts as that which reachcd physicians here.

Dr. MeCormack may rest assured that when I reprint my article for distribution, the Goebel reference will be wholly omitted; and $I$ beg once more to assure him of my regrets.

Respectfully, Robert H. M. Dawbarn, M.D.

\section{Arsenic in Pernicious Anemia and Leucocythemia.}

Baltimore, Mo., March 18, 1901.

To the Editor:-In Trie Jounnal of March 16, page 756 , the following words appear-a part of a summary of some remarks by me before the Johns Hopkins Hospital Medical Society: "He has been astonished to hear the value of arsenic in pernicious anemia and leucocythemia questioned recently by a distinguished Boston clinician. There is positive evidence of its usefulness in these conditions."

I regret to say that this report of my remarks is somewhat erroneous. I referred, in an informal discussion, to Dr. Cabot's interesting remarks before the Association of American Physicians, last summer (Pernicious Anemia: A Study of 110 Cases. Transactions of the Association of American Physicians, 1900, $\mathrm{xv}, 334$ ), and did express surprise that the author should regard arsenic of so little value in these cases, stating that it was my impression that in some instances it was of material benefit. I was far from stating, nor do I believe that the value of arsenic is by any means positively proven. And I am not aware that Dr. Cabot has questioned the value of arsenic in leukemia. Yours sincerely,

W. S. Thayer, M. 1).

\section{The Determination of Sex.}

Canton, OHIo, March, 9, 1901.

To the Editor:-Since you have considered it of sufficient importance to give editorial space to an article on the above subject, it may be of interest to know of a case where, for extrauterine pregnaney, it was necessary, in the laparotomy done for relief, to remove the left Fallopian tube and ovary. This woman, with a right ovary intact and a left ovary removed, has since given birth to two children, with an interval of several years between births. The first child was a female, the second a male. One would think that in this day there would be a sufficient number of mono-ovarian women giving birth to children, for one wishing to lay down a scientific theory, based on the hypothesis of ovarian determination of sex, to have led to in investigation of that phase of the subject for facts. Very truly,

Edward P. Morrow, M.D.

\section{Medico-Sociologic Data Wanted.}

Atlanta, Ga., March l.

To the Editor:-The sociological committee of the Tri-State Medical Society of Alabama, Georgia, and Tennessee desires information relative to any and all states that have enacted laws regulating marriage of criminals, insane, epileptics, tuberculous or those suffering with venereal disease. It also desires information of any legal enactments or literature on the subject of rendering habitual criminals sterile. Any information along this line, from any of your readers, will be greatly appreciated and gladly received.

R. R. Kime, Chairman.

308 and 310 Eng.-Amer. Building.

\section{Book 2Totices.}

The Medical Examination for life Insurance, and its Associated Clinical Methods, with Chapters on the Insurance of Substandard Lives and Accident Insurance. By Charles Lyman Greene, M.D., St. Paul, Minn., Clinical Professor of Medicine and Physical Diagnosis in the University of Min nesota. With 99 lllustrations. Cloth. Pp. 426. Price $\$ 4.00$. Philadelphia: P. Blakiston's Son \& Co. 1900.

Dr. Greene's treatise on medical examinations for life insurance is by far the most complete work on the subject extant. He states that the reason for the existence of this book is the introduction into medical schools of courses of lectures dealing especially with the inedical aspect of life insurance. The work is, however, of equal if not greater value to the medical examiner, who has heretofore had relatively little to guide him, with the exception of the somewhat antiquated treatises up to this time obtainable and the exceedingly brief instructions is sued to medical cxaminers by the respective insurance companies. The most valuable section is that which deals with the convintional questions found on examination blanks, their proper analysis and answers. It is gratifying to note that the author has obtained permission to use and insert the Nylie standard table of heights and weights. The influence of family history in modifying the value of risks is fully considered, as is also the effect of occupation on longevity and the incidence of disease. The section on examination of the chest is very well presented and excellently illustrated. One of the vexed ques. tions that confront the examiner is that of the significance of $a$ pulse which does not vary whether the applicant is sitting or standing, and this question does not seem to be considered by the author. The discussion of the examination of the urine iconcise and excellent, but nothing authoritative is stated regard ing the important points of the bearing of oceasional albuninuria, the so-called physiologic albuminuria, occasional glycosuria, and digestive glycosuria on the value of risks. The author merely quotes, without especial comment, the already published dicta of certain medical directors regarding these matters. A unique chapter is that on the insurance of sub standard lives-a class of risks which nowadays is attracting a great deal of attention among the so-called "old-line" com. panies. The last two chapters of the volume are devoted to fraud and to aceident insurance. The book, taken as a whole. is commendable and marks a great advance in the literature of this important subject.

T'ue Care of tue Consumptive. A Consideration of the Scien tific Use of Natural Therapeutic Agencies in the Prevention and Cure of Consumption; Together with a Chapter on Colorado as a Resort for Invalids. By Charles Fox Gar dincr, M.D., Non-resident Fellow of the New York Academy of Medicine. Cloth. Pp. 182. Price, \$1.25. New York anil London: G. P. Putnam's Sons. 1900.

The author states that his object is to give in a clear and practical way the rules which should govern the consumptive in the use of fresl air, sunlight, food, rest and exercise, so that these naturnl beneficial agencies shall be applied to the best advantage. These are, as he maintains, still the best, most convenient and durable of any curative methods applied in the disease. The book is brief in its treatment of the subject, but seems to be amply full for its purpose, while the advice on the whole is excellent. The latter third of the work is given to a description of the climate of Colorado and its advantages. in which it is shown how many consumptives can make their residence thcre and obtain perfect health. The author be lieves that the nervous system does not suffer from high altitudes and the typical nervous invalid is not necessarily a contraindication to resort to that section. It is interesting to note how writers of elaborate works on consumption are more conservative than many who merely repeat the prevalent views. This one apparently does not favor the extreme theories of contagion that are held. An impaired vital activity giving the germs, so universally diffused, a chance is, he holds, the more important factor, and he uses as his argument the experience of Colorado Springs, where the danger from contagion should be the greatest, if the views held by many were correct. 